\title{
Erratum to: Evidence for somatic transcription of male-transmitted mitochondrial genome in the DUI species Ruditapes philippinarum (Bivalvia: Veneridae)
}

Liliana Milani • Fabrizio Ghiselli •

Mariangela Iannello $\cdot$ Marco Passamonti

Published online: 9 September 2014

(C) Springer-Verlag Berlin Heidelberg 2014

Erratum to: Curr Genet (2014) 60:163-173

DOI 10.1007/s00294-014-0420-7

Unfortunately, the electronic supplementary files have been excluded in the original publication. The electronic supplementary files are now linked with this erratum.

The online version of the original article can be found under doi:10.1007/s00294-014-0420-7.

Electronic supplementary material The online version of this article (doi:10.1007/s00294-014-0449-7) contains supplementary material, which is available to authorized users.

L. Milani $(\bowtie) \cdot$ F. Ghiselli · M. Iannello $\cdot$ M. Passamonti Dipartimento di Scienze Biologiche, Geologiche ed Ambientali, University of Bologna, Via Selmi 3, 40126 Bologna, Italy

e-mail: liliana.milani@unibo.it 